\title{
Will souped up salmon sink or swim?
}

\section{A company in}

Massachusetts is seeking permission to market salmon genetically modified to grow faster than normal. Tony

Reichhardt explores the potential ecological risks, should the fish escape from salmon farms.

A few years ago, when Garth Fletcher's office telephone rang, it was usually another scientist wanting to talk about aquaculture or fish genetics. Nowadays, it is just as likely to be a news reporter asking barbed questions about 'Frankenfish'. "We're getting hit every day in the press," he says.

Fletcher is president of the Canadian arm of Aqua Bounty Farms, a company based in Waltham, Massachusetts, that hopes to bring genetically modified (GM) salmon to the dinner plates of North America. At the company's experimental hatchery on Canada's Prince Edward Island, its aquaculturists are raising Atlantic salmon (Salmo salar) modified to carry a growth-hormone gene from the Pacific chinook salmon (Oncorhynchus tshawytscha), which is hooked to a powerful promoter sequence. This boosts the fishes' growth rate, so that they reach market size quicker ${ }^{1}$.

Aqua Bounty Farms, formerly a subsidiary of the company A/F Protein, has

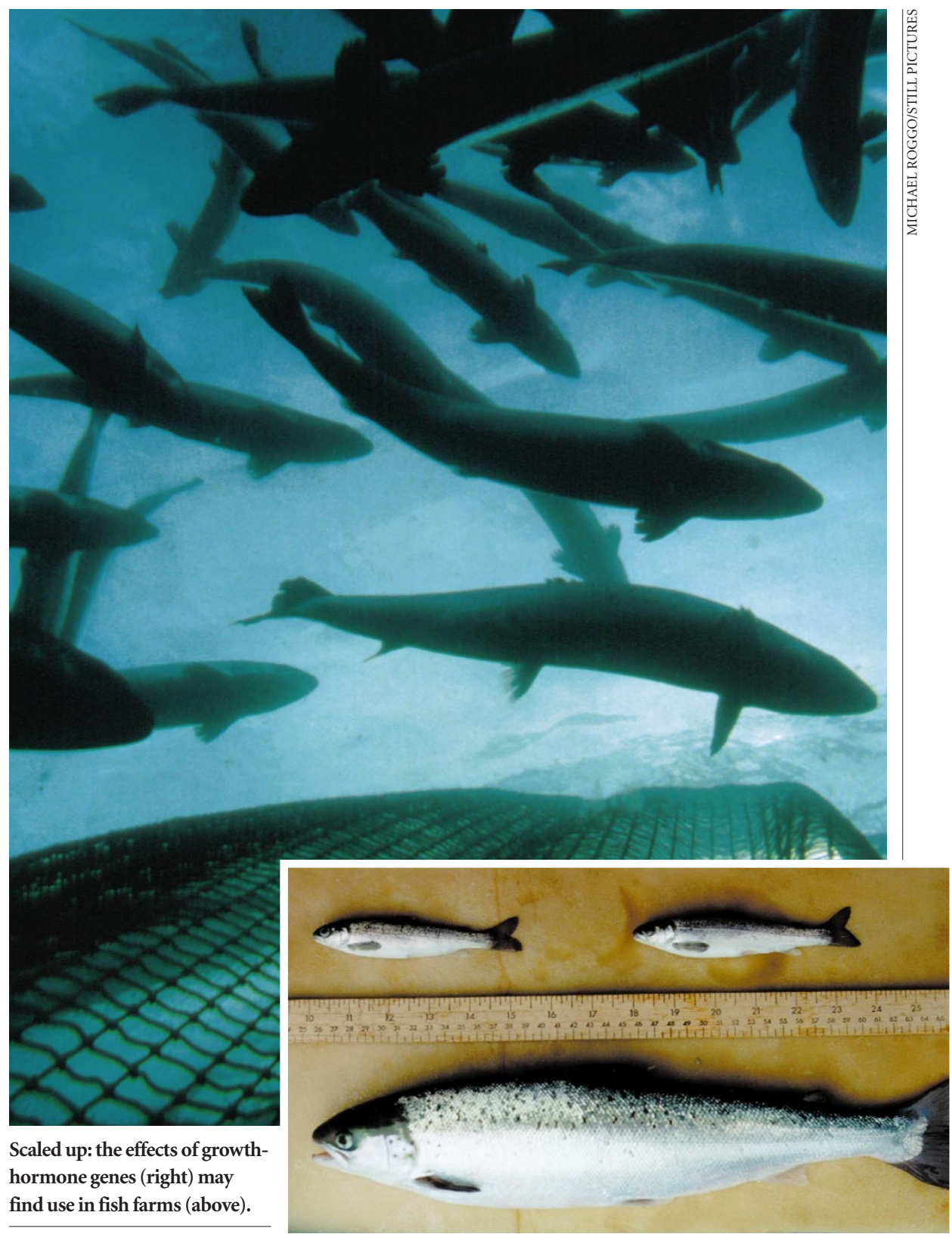

applied to the US Food and Drug Administration (FDA) for permission to market its salmon. And ever since this application was picked up by the media, the company has been plunged into the thick of the controversy surrounding GM foods - which, after a slow start compared with the furore in Europe, is now beginning to register in North America. Some ecologists have even warned that transgenic salmon could wipe out natural populations of related fish should they escape into the wild.

So far, the only things that have been wiped out are the business plans of two companies that licensed A/F Protein's geneinsertion technology in the 1990s. Both Otter Ferry Salmon in Scotland and the New Zealand King Salmon Company scrapped their GM salmon research after unfavourable publicity. But with Aqua Bounty Farms still pressing ahead, ecologists warn that the current state of scientific knowledge is inadequate to provide a full assessment of the risks posed by the company's fish. "There's just so much speculation compared to the amount of data," says Robert Devlin, a researcher with Canada's Department of Fisheries and Oceans, based in West Vancouver. Much of the research only started in the past decade. Because it can take 10 years to produce a stable line of transgenic salmon, says Devlin, the dearth of experimental studies is hardly surprising.

Research on transgenic strains is currently under way for some 35 species of fish worldwide, including Pacific salmon such as the chinook and coho (Oncorhynchus kisutch), various other members of the salmonid family, and other economically important fish including catfish and tilapia. Most of the work is being done by commercial fisheries and involves growth-hormone genes.

The one certainty is that conventionally farmed salmon, typically raised in netted pens 


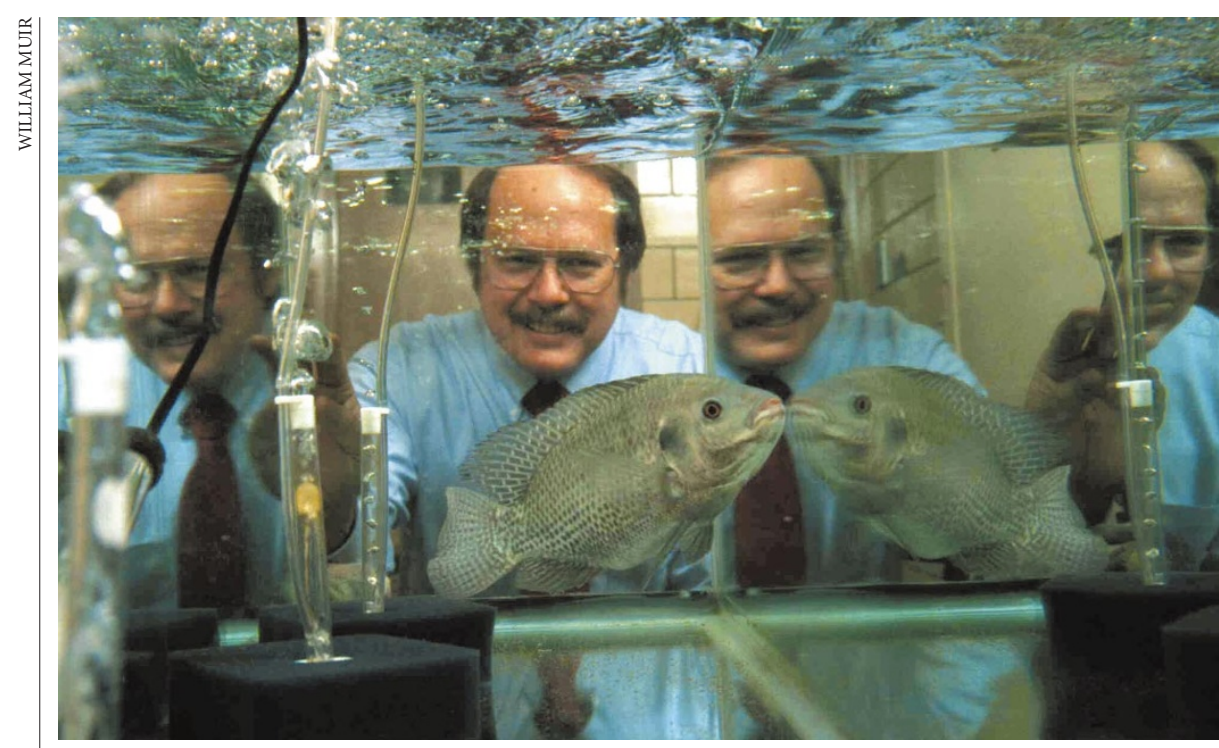

Trojan genes: Muir's research has raised fears that wild salmon may be decimated by GM fish.

in shallow coastal waters, will escape. Where there are salmon farms, farmed fish tend to turn up in salmon streams - in some cases outnumbering their wild counterparts. In western Canada and in Washington state, south of the US border, ecologists are becoming particularly concerned about the effects of escaping Atlantic salmon - which number tens, if not hundreds, of thousands - on already declining Pacific salmon populations.

\section{The salmon run}

Whether transgenic salmon pose a special risk is uncertain, but the potential problems are clear enough. One worry is that escaped GM fish will breed with their wild counterparts and release their added growthhormone genes into wild populations, with unpredictable consequences. Proponents of the technology counter that it is possible to make the transgenic fish sterile - and if Aqua Bounty Farms' Atlantic salmon were farmed off the Pacific coast of British Columbia and the northwest United States, they would be unlikely to breed successfully with native Pacific salmon species.

Even if fast-growing GM fish do not spread their genes to their wild counterparts, they could disrupt the ecology of salmon streams by competing with native fish for resources. The consequences will depend on many factors, including the health of the local population, the number and specific genetic strain of the escaped fish, and the local environment.

On the question of interbreeding, alarming results have come from laboratory studies conducted by William Muir and Richard Howard of Purdue University in West Lafayette, Indiana. Using the fast-breeding Japanese medaka (Oryzias latipes) as an experimental model, Muir and Howard looked at the role of size in mating success, and found that big medaka males had a fourfold advantage over their smaller competitors.

The researchers then compared the via- bility of normal medaka with another group to which they had added a human growthhormone gene. Under aquarium conditions, the fast-growing GM fish were 30\% more likely to die before reaching sexual maturity. The final step was to plug these and other results into a computer to model to see what would happen when 60 transgenic fish were introduced into a population of 60,000 wild medaka. The results were disturbing. It took only 40 generations for the GM fish, which mated more successfully but produced offspring that did not survive as well, to drive the population to extinction. Muir and Howard called it the "Trojan gene effect" 2 .

The Purdue researchers stressed that their results should be treated with caution. Among other things, the dire prediction of population extinction assumed that mature transgenic fish would be bigger than their wild counterparts - whereas the human growth-hormone gene only increased the medaka's juvenile growth rate, and produced adult fish no bigger than average. Muir has since been experimenting with the gene for a salmon growth hormone and has found that it can make adult medaka grow up to $50 \%$ larger than normal. The viability of these fish was even worse - their survival to sexual maturity was reduced by as much as $78 \%$ compared with wild-type medaka, which suggests that they could wipe out a wild population very quickly. These results have yet to be published, but make the Trojan gene seem like a real threat if the techniques used to make GM fish sterile prove less than $100 \%$ reliable.

\section{Shock treatment}

Creating sterile salmon is relatively simple. If salmon eggs are subjected to a heat or pressure shock shortly after fertilization, they retain an extra set of chromosomes, ending up with three sets, rather than the normal two. The resulting 'triploid' fish do not develop normal sexual characteristics, and the females are sterile. It is also possible to raise female salmon as fertile males by treating them with male sex hormones. So by using these 'sex reversed' males — which will be able to produce only female offspring - as breeding stock, and applying a pressure shock to the eggs that they fertilize, it should be possible to raise GM salmon that consist entirely of sterile, triploid females.

Fletcher argues that skilled aquaculturists can apply this method unerringly, but other scientists are less confident. "Even when you're pretty good at it, you get a lot of batch to batch variation," argues Anne Kapuscinski, a specialist in biotechnology and aquaculture at the University of Minnesota in St Paul.

\section{A growing problem?}

But even if sterility cannot be guaranteed, will Aqua Bounty Farms' salmon grow into oversized adults that have an advantage in the mating game? That is the "million dollar question", says Kapuscinski. Commercial fish farmers are only interested in having salmon that grow to market size faster, and Fletcher says the company's studies have found "zero evidence" that the transgenic salmon are bigger after they reach sexual maturity. But other scientists point out that these results have not been published in the peer-reviewed literature. "No one outside of their circle has seen those data," complains Eric Hallerman, a fisheries biologist at the Virginia Polytechnic Institute in Blacksburg.

Devlin, who has raised growth-enhanced transgenic coho salmon in the lab, finds that they are about $50 \%$ larger at sexual maturity than their wild counterparts. But that may in part reflect the difference between cosy lab conditions and the harsh natural environment. The key test is to grow transgenic and wild-type fish under identical conditions. When scientists at the Center for Genetic Engineering and Biotechnology in Havana, Cuba, conducted such experiments with GM tilapia, the genetically engineered fish grew up to twice as large at maturity as nontransgenic fish ${ }^{3}$. So far, no one has published this type of experiment with salmon.

Studies addressing the ability of transgenic salmon to disrupt ecosystems irrespective of their ability to interbreed with wild populations have yielded similarly inconclusive results. Devlin and his colleagues, for instance, have found that growth-enhanced transgenic coho salmon eat nearly three times as much food as their natural counterparts under laboratory conditions $s^{4}$ - their elevated growth-hormone levels appear to make them hungrier. Whether this would hold true in the wild is uncertain. But if so, the transgenic fish, which also mature faster, could be foraging ravenously at times when natural food availability in a particular stream is low, which could seriously disrupt its ecology. 
Arnold Sutterlin of Aqua Bounty Farms, working with Mark Abrahams of the University of Manitoba in Winnepeg, has conducted similar experiments with growthenhanced Atlantic salmon. Again, the fish were hungrier, but they were also less careful about avoiding predators - judged by experiments in which young fish had to get their food from a portion of a tank containing a large trout ${ }^{5}$. This, together with the observation that young transgenic Atlantic salmon appear to have less effective camouflage, should mean that they are less likely to survive in the wild, minimizing the ecological damage that escaping fish might cause.

Devlin and his colleagues also report that their transgenic coho are slower swimmers ${ }^{6}$. But Aqua Bounty Farms' scientists have found that the GM Atlantic salmon appear more active than the wild-type fish ${ }^{5,7}$. These varying results may reflect the different species being studied, or just the strain-to-strain variations caused by the vagaries of transgenic technology. Depending on where exactly the extra genes are incorporated into the fish genome, they can exert subtly different effects. For example, although Muir's experiments with a salmon growth-hormone gene in medaka showed that survival to sexual maturity was depressed by up to $78 \%$, in some strains the figure was only $40 \%$. To conduct an accurate environmental risk assessment for GM fish, he says, you need to evaluate each genetic line individually. "We're not sure of all the reasons why," says Muir, "but every transgenic founder is unique."

To Devlin, the catalogue of scientific uncertainties shows why more research is desperately needed. And it will not come cheap. "These are not small experiments," he says. "When you're talking about raising a family of transgenic fish, it's not a vial. It's large tanks." Muir would start by conducting aquarium experiments to test how transgenic fish compare with normal fish over a range of parameters related to their biological 'fitness'. In the manner of his medaka experiments, he would then generate a computer model to consider the likely impact of the fish in wild populations. To this Devlin would add laboratory studies that simulate stream conditions. Even better, says ecologist Jeff Hutchings of Dalhousie University in Halifax, Nova Scotia, would be to conduct tests in the wild, blocking off a portion of a stream to prevent fish escaping into a larger aquatic system. Whether it would be feasible to isolate streams in this way is unclear and any experiment involving the deliberate environmental release of a transgenic animal is likely to prove highly controversial.

The FDA is still considering Aqua Bounty

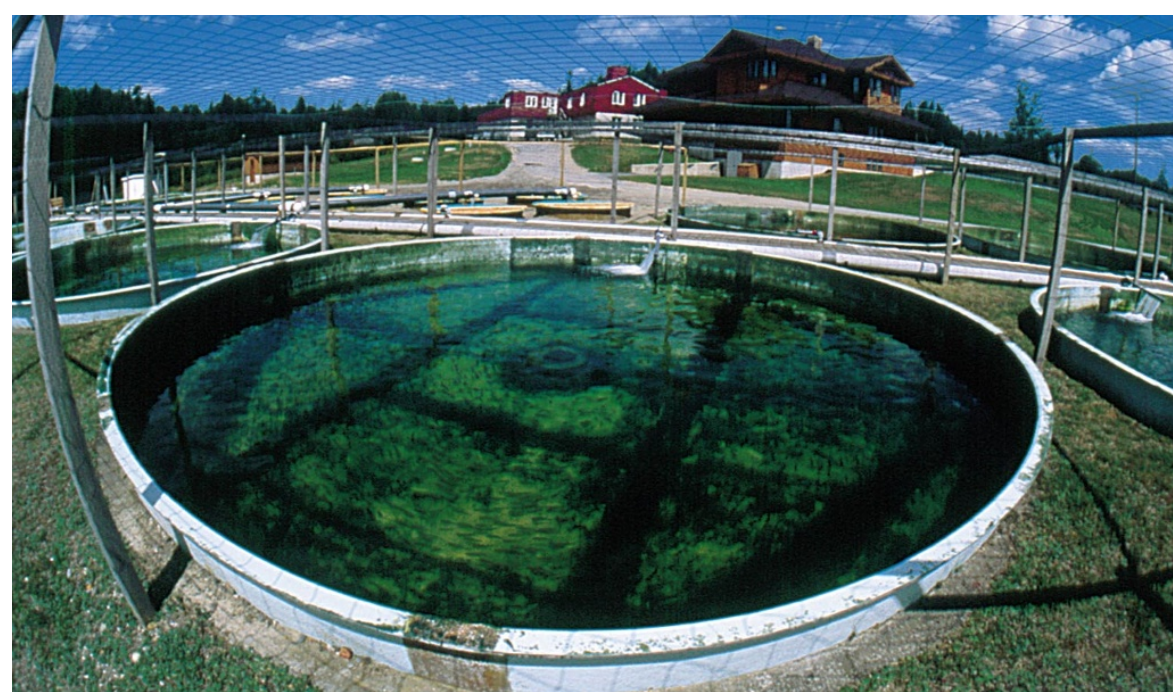

Coming ashore: concerns about damage to wild salmon (left) may force fish farms inland (above).

is relatively cheap, costing only 20 cents per fish, claims Kapuscinski. But any regulations preventing GM salmon from being raised in coastal waters would pose problems. Production of Atlantic salmon is presently conducted almost exclusively in sea pens. Unless the performance of transgenic salmon becomes truly remarkable, Fletcher believes it is unlikely that a sizeable portion of the industry would switch to contained land-based, pumped systems given their high capital and operating costs.

But Elliot Entis, chief executive officer of Aqua Bounty Farms, takes a more sanguine view. Even if the FDA imposed a ban on the rearing of growth-enhanced GM salmon in coastal net pens, he believes the transgenic fish could become a viable economic proposition in the long term. The UN Food and Agriculture Organization predicts that global aquacultural production will more than double over the coming decade. Given that coastal aquaculture is already causing ecological damage, by spreading fish diseases, modifying habitats, causing nutrient pollution, and through the escape of exotic farmed fish ${ }^{8}$, Entis believes regulators may eventually demand that fish farms move from coastal pens to contained ponds. "A lot of salmon farming is going to move inland regardless," he says. If so, argues Entis, fast-growing transgenic salmon might be just what the industry needs to remain economically competitive. Tony Reichhardt writes from Washington for Nature.

1. Hew, C. L., Fletcher, G. L. \& Davies, P. L. J. Fish Biol. Suppl. A 47, 1-19 (1995).

2. Muir, W. M. \& Howard, R. D. Proc. Natl Acad. Sci. USA 96, 13853-13856 (1999).

3. de la Fuente, J., Guillen, I., Martinez, R. \& Estrada, M. P. Genet. Anal. Biomol. Eng. 15, 85-90 (1999).

4. Devlin, R. H. et al. Aquaculture Res. 30, 479-482 (1999).

5. Abrahams, M. V. \& Sutterlin, A. Anim. Behav. 58, 933-942 (1999).

6. Farrell, A. P., Bennet, W. \& Devlin, R. H. Can. J. Zool. 75, 335-337 (1997).

7. Stevens, E. D., Sutterlin, A. \& Cook, T. J. Can. J. Fisheries Aquat. Sci. 55, 2028-2035 (1998)

8. Naylor, R. L. et al. Nature 405, 1017-1024 (2000).

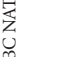

